\title{
Doses e fontes de nitrogênio na recuperação das características estruturais e produtivas do capim-marandu ${ }^{1}$
}

\author{
Rates and sources of nitrogen in the recovery of the structural and productive \\ characteristics of marandu grass
}

\author{
Douglas Ramos Guelfi Silva ${ }^{2 *}$, Kátia Aparecida de Pinho Costa ${ }^{3}$, Valdemar Faquin ${ }^{2}$, Itamar Pereira de Oliveira ${ }^{4}$ \\ e Thiago Fernandes Bernardes 5
}

\begin{abstract}
RESUMO - A reconstituição da fertilidade do solo é um dos caminhos para se recuperar a capacidade produtiva da pastagem em degradação. A adubação nitrogenada é fundamental para o aumento da produção de forragem, principalmente, quando se trata da recuperação de pastagens. Diante disso, o objetivo do trabalho foi avaliar as características estruturais e o acúmulo de massa seca (MS) de lâminas foliares e colmos mais bainhas do capim-marandu de pastagem em estágio moderado de degradação, sob doses e fontes de nitrogênio $(\mathrm{N})$, por três anos. O experimento foi conduzido de julho de 2003 a março de 2006, na Fazenda Modelo da Universidade Estadual de Goiás (UEG), em uma área de $882 \mathrm{~m}^{2}$, com parcelas de $20 \mathrm{~m}^{2}$ e área útil de $6 \mathrm{~m}^{2}$. O delineamento experimental utilizado foi o de blocos ao acaso, com três repetições. Os tratamentos nas parcelas foram caracterizados pelo fatorial $2 \times 4$, sendo duas fontes de $\mathrm{N}$ (sulfato de amônio e uréia) e quatro doses de $\mathrm{N}(0 ; 100$; 200 e $\left.300 \mathrm{~kg} \mathrm{ha}^{-1} \mathrm{ano}^{-1}\right)$. Na subparcela, os tratamentos foram representados pelos anos (2004; 2005 e 2006), referentes ao tempo de recuperação da pastagem. A adubação nitrogenada foi parcelada em três aplicações, após cada corte de avaliação da forrageira. Os resultados obtidos mostraram que a adubação nitrogenada influenciou as características estruturais e o acúmulo de massa seca do capim-marandu, e, consequentemente, a sua recuperação. A dose de $300 \mathrm{~kg} \mathrm{ha}^{-1}$ ano $^{-1}$ de sulfato de amônio proporcionou maiores valores de altura de plantas, densidade de perfilhos e massa seca das lâminas foliares.
\end{abstract}

Palavras-chave: Urochloa brizantha. Adubação Nitrogenada. Sulfato de Amônio. Uréia.

\begin{abstract}
To replenish soil fertility is one of the ways of recovering the productive capacity of degraded pasture. Nitrogen fertilisation is fundamental to increasing forage production, especially when it comes to the recovery of pasture. With this in mind, the objective of this work was to evaluate the structural characteristics and dry matter (DM) accumulation of the leaf blades and sheathed stems of marandu-grass pasture at a moderate stage of degradation, for different dosages and sources of nitrogen, during a three-year period. The experiment was carried out from July, 2003 to March, 2006 at the Model Farm of the Goiás State University (UEG), over an area of $882 \mathrm{~m}^{2}$ with plots of $20 \mathrm{~m}^{2}$ and usable area of $6 \mathrm{~m}^{2}$. The experimental design was of randomized blocks with three replications. The treatments in the plots were characterized by a $2 \times 4$ factorial, being two nitrogen sources (ammonium sulphate and urea) and four nitrogen dosages $\left(0 ; 100 ; 200\right.$ and $\left.300 \mathrm{~kg} \mathrm{ha}^{-1} \mathrm{yr}^{-1}\right)$. For each sub-plot, treatments were represented by the years $(2004,2005$ and 2006), as relating to the time of the recovery of the pasture. Nitrogen fertilization was divided into three applications, following each harvesting of the grass for forage evaluation. The results showed that nitrogen fertilisation influenced the structural characteristics and dry matter accumulation of marandu grass, and hence its recovery. The dosage of $300 \mathrm{~kg} \mathrm{ha}^{-1} \mathrm{yr}^{-1}$ of ammonium sulphate resulted in greater values for plant height, tiller density and leaf-blade dry matter.
\end{abstract}

Keywords: Urochloa brizantha. Nitrogen Fertilisation. Ammonium Sulphate. Urea.

\footnotetext{
*Autor para correspondência

'Recebido para publicação em 02/09/2011; aprovado em 25/06/2012

Parte da Dissertação de Mestrado do primeiro autor apresentada ao Programa de Pós-Graduação em Ciência do Solo da Universidade Federal de Lavras

${ }^{2}$ Departamento de Ciência do Solo, Universidade Federal de Lavras/UFLA, Lavras-MG, Brasil, 37.200-000, douglasguelfi@dcs.ufla.br, vafaquin@ dcs.ufla.br ${ }^{3}$ Instituto Federal de Educação, Ciência e Tecnologia Goiano/IF Goiano, Rio Verde-GO, Brasil, katiazoo@ hotmail.com

${ }^{4}$ Embrapa Arroz e Feijão, Santo Antônio de Goiás-GO, Brasil, itamar@cnpaf.embrapa.br

${ }_{5}^{5}$ Departamento de Zootecnia, Universidade Federal de Lavras/UFLA, Lavras-MG, Brasil, 37.200-000, thiagobernardes@dzo.ufla.br
} 


\section{INTRODUÇÃO}

A aplicação de fertilizantes em áreas de pastagens é uma forma de fornecer os nutrientes para atender as necessidades metabólicas e promover o melhor desenvolvimento das forrageiras. A adubação, especialmente a nitrogenada, é fundamental para o aumento da produção de biomassa, principalmente quando se trata da recuperação de pastagens. Vários pesquisadores reportaram melhorias na estrutura do pasto e aumento da produção de biomassa mediante a utilização de adubação nitrogenada (COSTA et al., 2009; FLORES et al., 2008; MESQUITA et al., 2010).

Normalmente, a resposta das plantas forrageiras ao nitrogênio tem sido avaliada pela produção de massa seca da parte aérea (BRAGA et al., 2009; EUCLIDES et al., 2007). Porém, não se pode esquecer que existem outras características estruturais importantes que influenciam a produção. Dentre elas, estão: a altura de plantas, densidade de perfilhos, área foliar e relação folha: colmo, que são características que estão diretamente relacionadas à produção de massa seca, recuperação das pastagens e ao comportamento ingestivo dos animais em condições de pastejo (SANTOS et al., 2010).

Dessa forma, estratégias de manejo da pastagem, como a adubação nitrogenada, são muito importantes porque podem ajudar a oferecer ao animal uma estrutura de dossel que possa otimizar as ações de manejo da forrageira (CARVALHO; SILVA; CARNEVALLI , 2000).

Nestecontexto, dois aspectos domanejo da adubação nitrogenada são fundamentais para as características estruturais das forrageiras: a fonte e o parcelamento das doses de nitrogênio, visando, principalmente, diminuir as perdas por volatilização, desnitrificação e por lixiviação. Com isso, tem-se melhor aproveitamento do nitrogênio pela planta, redução das perdas e manutenção de taxas de acúmulo de massa seca pela planta mais uniforme (WERNER; COLUZZA; MONTEIRO, 2001).

Além disso, o conhecimento de como a adubação nitrogenada interfere nas características estruturais de uma pastagem degradada é fundamental para o manejo da mesma considerando ainda que refletirá no comportamento ingestivo e, consequentemente, no desempenho animal na área de pastejo.

Dessa forma, devido à grande importância da adubação nitrogenada na recuperação e manejo das pastagens, objetivou-se avaliar as características estruturais e o acúmulo de massa seca de lâminas foliares e colmos mais bainhas, sob doses e fontes de nitrogênio, por três anos, em pasto de capimmarandu em estágio moderado de degradação.

\section{MATERIAL E MÉTODOS}

O experimento foi conduzido de julho de 2003 a março de 2006, em condições de campo na cidade de São Luís de Montes Belos - GO, a 579 m de altitude, 16³1’30”de latitude Sul e 50'22'20" de longitude Oeste. A área utilizada de pastagem foi de $882 \mathrm{~m}^{2}$, dividida em três blocos de $294 \mathrm{~m}^{2}$, com parcelas individuais de $20 \mathrm{~m}^{2}$ e área útil de $6,0 \mathrm{~m}^{2}$.

O delineamento experimental utilizado foi o de blocos completos ao acaso, com três repetições. Nas parcelas principais foi utilizado o esquema fatorial $2 \times 4$, sendo duas fontes de $\mathrm{N}$ (sulfato de amônio e uréia) e quatro doses de $\mathrm{N}\left(0 ; 100 ; 200\right.$ e $\left.300 \mathrm{~kg} \mathrm{ha}^{-1} \mathrm{ano}^{-1}\right)$. Na subparcela, os tratamentos foram representados pelos anos (2004; 2005 e 2006), referentes ao tempo de recuperação da pastagem de Brachiaria brizantha cv. Marandu.

Durante a condução do experimento foram monitorados diariamente os dados de temperaturas mínimas, médias, máximas e precipitação pluviométrica (Figura 1).

O solo foi classificado originalmente como Latossolo Vermelho eutrófico (EMPRESA BRASILEIRA DE PESQUISA AGROPECUÁRIA, 2006), de textura argilosa. Foram realizadas análises químicas do solo nos anos de 2003, 2004 e 2005 na profundidade de 0-20 cm (Tabela 1).

No primeiro ano (2003), foram aplicados $500 \mathrm{~kg} \mathrm{ha}^{-1}$ de calcário dolomítico com $85 \%$ de PRNT, em cobertura 60 dias, antes do período chuvoso. Em setembro, após as primeiras chuvas foram aplicados $150 \mathrm{~kg} \mathrm{ha}^{-1} \mathrm{de}_{2} \mathrm{O}_{5} 18 \mathrm{~kg}$ de $\mathrm{S} \mathrm{ha}^{-1}, 80 \mathrm{~kg}$ de $\mathrm{K}_{2} \mathrm{O} \mathrm{ha}{ }^{-1}$ e $30 \mathrm{~kg}$ de fritas (FTE BR12) $\mathrm{ha}^{-1}$, utilizando-se como fontes: superfosfato simples, cloreto de potássio e fritas, respectivamente. A partir dos resultados da análise da amostra de solo do segundo ano (2004), foi realizada a adubação de manutenção com $50 \mathrm{~kg}$ de $\mathrm{P}_{2} \mathrm{O}_{5} \mathrm{ha}^{-1}, 6 \mathrm{kgde} \mathrm{Sha}^{-1}$ e $100 \mathrm{~kg}$ de $_{2} \mathrm{O} \mathrm{ha}^{-1}$, provenientes das fontes de superfosfato simples e cloreto de potássio, respectivamente. No terceiro ano de recuperação (2005), foram aplicados $150 \mathrm{~kg}$ de $\mathrm{P}_{2} \mathrm{O}_{5} \mathrm{ha}^{-1}, 18 \mathrm{~kg}$ de S ha-1, $120 \mathrm{~kg}$ de $\mathrm{K}_{2} \mathrm{O}$ ha $^{-1}$ e $20 \mathrm{~kg}$ de fritas (FTE BR-12) ha ${ }^{-1}$, na forma de superfosfato simples, cloreto de potássio e fritas, respectivamente. A adubação de manutenção foi realizada de acordo com Sousa e Lobato (2004), sendo toda adubação realizada com uma única aplicação a lanço no início do período chuvoso (setembro), antes dos fertilizantes nitrogenados.

A adubação nitrogenada, em cada ano, foi parcelada em três épocas, após cada corte de avaliação da forrageira, sendo que a primeira aplicação foi realizada em dezembro, a segunda em janeiro e a terceira em fevereiro, todas com intervalo de 30 dias.

Antes de cada colheita da forrageira, mediu-se a altura das plantas, com metro de bambu, do nível do solo até a altura da folha mais alta, em cinco pontos da área útil de cada parcela. 
Figura 1 - Temperaturas máximas e mínimas e precipitações pluviais observadas durante o período de setembro de 2003 a fevereiro de 2006

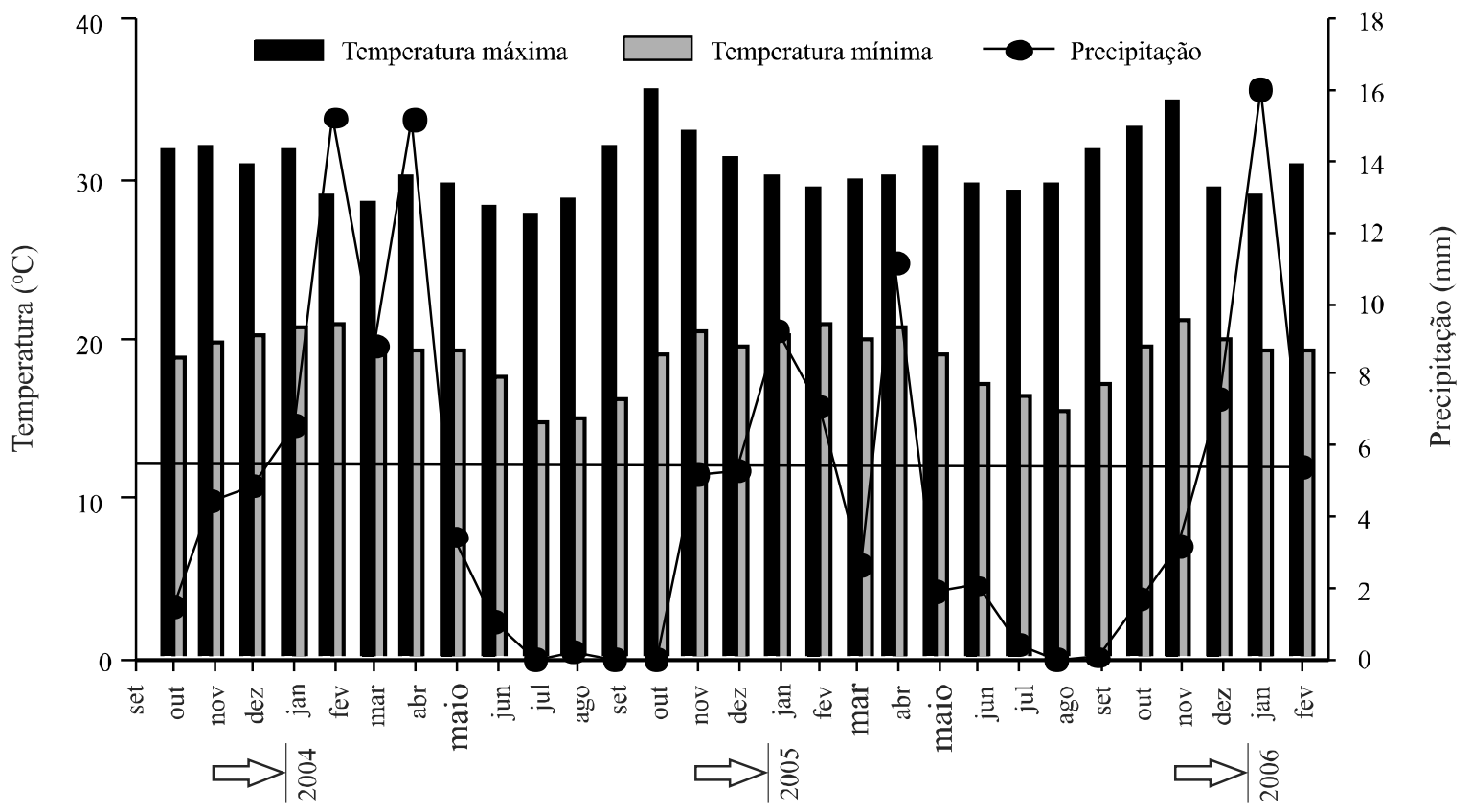

Meses do ano

Tabela 1 - Características químicas do solo antes da adubação de manutenção e dos tratamentos, nos anos de condução do experimento

\begin{tabular}{|c|c|c|c|}
\hline Características & 2003 & 2004 & 2005 \\
\hline $\mathrm{pH}\left(\mathrm{CaCl}_{2}\right)$ & 5,2 & 5,1 & 4,6 \\
\hline 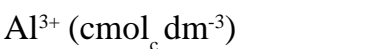 & 0,0 & 0,1 & 0,2 \\
\hline $\mathrm{H}^{+} \mathrm{Al}\left(\mathrm{cmol}_{\mathrm{c}} \mathrm{dm}^{-3}\right)$ & 3,9 & 5,3 & 3,5 \\
\hline $\mathrm{Ca}^{2+}\left(\mathrm{cmol}_{\mathrm{c}} \mathrm{dm}^{-3}\right)$ & 2,70 & 2,79 & 2,20 \\
\hline $\mathrm{Mg}^{2+}\left(\mathrm{cmol}_{\mathrm{c}} \mathrm{dm}^{-3}\right)$ & 1,00 & 0,91 & 0,23 \\
\hline $\mathrm{K}^{+}\left(\mathrm{cmol}_{\mathrm{c}} \mathrm{dm}^{-3}\right)$ & 0,42 & 0,23 & 0,11 \\
\hline $\mathrm{P}_{\text {Mehlich-1 }}\left(\mathrm{mg} \mathrm{dm}^{-3}\right)$ & 1,3 & 6,4 & 1,8 \\
\hline $\mathrm{SO}_{4}^{-2}\left(\mathrm{cmol}_{\mathrm{c}} \mathrm{dm}^{-3}\right)$ & 9,8 & 18,9 & 30,0 \\
\hline $\mathrm{Cu}^{2+}\left(\mathrm{mg} \mathrm{dm}^{-3}\right)$ & 0,4 & 1,7 & 1,0 \\
\hline $\mathrm{Zn}^{2+}\left(\mathrm{mg} \mathrm{dm}^{-3}\right)$ & 0,2 & 2,9 & 0,7 \\
\hline $\mathrm{Fe}^{2+}\left(\mathrm{mg} \mathrm{dm}^{-3}\right)$ & 13,0 & 30,0 & 31,3 \\
\hline $\mathrm{Mn}^{2+}\left(\mathrm{mg} \mathrm{dm}^{-3}\right)$ & 27,4 & 41,0 & 15,6 \\
\hline Matéria orgânica $\left(\mathrm{g} \mathrm{dm}^{-3}\right)$ & 11,0 & 18,0 & 20,0 \\
\hline CTC a pH 7,0 $\left(\mathrm{cmol}_{\mathrm{c}} \mathrm{dm}^{-3}\right)$ & 8,0 & 8,2 & 6,5 \\
\hline
\end{tabular}

A planta forrageira foi coletada com auxílio de um quadrado de ferro de $1,0 \times 1,0 \mathrm{~m}$ e cortada com tesoura de aço à altura de $20 \mathrm{~cm}$ da superfície do solo. Após cada corte de avaliação, foi realizado o corte de uniformização de toda a área experimental na mesma altura de corte das plantas avaliadas, sendo retirado da área o resíduo dessa uniformização.

O material coletado no campo foi acondicionado em sacos plásticos e enviado ao laboratório, onde foi retirada uma amostra representativa de cada parcela, de aproximadamente $500 \mathrm{~g}$. Posteriormente, o material foi colocado em estufa de ventilação forçada de ar, com temperatura entre 58 e $65{ }^{\circ} \mathrm{C}$ por $72 \mathrm{~h}$, para secagem, moídas em moinho tipo Willey, em peneiras com crivo de um milímetro e armazenadas em sacos plásticos.

Para a determinação da relação folha:colmo, uma amostra de 15 plantas de cada parcela foi levada para o laboratório para a separação manual dos componentes morfológicos: folha (lâminas foliares), colmos (colmos e pseudocolmos) e material morto. Em seguida, as lâminas e os colmos foram acondicionados separadamente em sacos de papel, identificados e secos, em estufa de ventilação forçada, a $65^{\circ} \mathrm{C}$ até atingirem peso constante. Os valores obtidos de massa seca total foram extrapolados para valores equivalentes em $\mathrm{kg} \mathrm{ha}^{-1}$.

Com os dados do peso seco de lâminas foliares e de colmos, foram determinadas a massa seca das lâminas foliares (MSLF), a massa seca de colmos mais bainhas, a relação folha:colmo (RFC), percentagem de lâminas foliares e a massa seca de colmos mais bainhas. 
Essa mesma amostra de folha (lâminas foliares) foi passada em um aparelho medidor de área foliar portátil (AREA METTER $\Delta \mathrm{T}$, modelo LI $3100 \mathrm{Li}$-cor, USA), para determinação do índice de área foliar.

Conhecendo-se a proporção de lâminas foliares e a produção de MS na área útil, estimou-se o peso da MS total de lâminas foliares (PSL), presentes em $1,0 \mathrm{~m}^{2}$ e a estimativa da área foliar total das plantas (AF), presente na área útil, foi obtida multiplicando-se o PSL, presente na área útil, pela área laminar das 15 plantas e dividindo-se o produto pelo peso da MS de lâminas foliares das 15 plantas. O IAF foi determinado pela equação 1. (SANTOS et al., 2006).

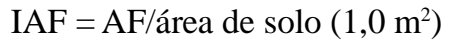

As mensurações da densidade populacional de perfilhos foram realizadas com armações metálicas de $0,12 \mathrm{~m}^{2}$ (40 x $60 \mathrm{~cm}$ ). Esses retângulos foram alocados em pontos representativos das condições da pastagem (altura média) no momento da amostragem. Com os dados obtidos na contagem dos perfilhos presentes na área da armação metálica, foi calculada a densidade de perfilhos por $\mathrm{m}^{2}$.

Foi realizada análise de variância pelo software SISVAR 4.6. (FERREIRA, 2003) e, em função da significância obtida para as variáveis, foram ajustadas equações de regressão polinomial, utilizando-se o nível de significância de $5 \%$ em todos os testes estatísticos.

\section{RESULTADOS E DISCUSSÃO}

Houve interação $(\mathrm{P}<0,05)$ entre doses e anos de recuperação da pastagem e doses e fontes de nitrogênio para a altura de plantas do capim-marandu. Para a interação doses de nitrogênio e anos verificou-se ajuste linear para a regressão no ano de 2005 (Figura 2a). Já nos anos de 2004 e 2006 o comportamento foi quadrático (negativo e positivo, respectivamente), e os pontos mínimos e máximos foram de 10,08 e 45,62 kg ha-1 ano-1 $^{-1}$, respectivamente.

Os maiores valores médios da altura de plantas (78 cm; $89 \mathrm{~cm} ; 77 \mathrm{~cm}$ ) ocorreram na dose de $300 \mathrm{~kg}$ ha $^{-1}$ ano $^{-1}$, mostrando aumento de $160 ; 85$ e $114 \%$ em relação à testemunha $(30 \mathrm{~cm} ; 48 \mathrm{~cm} ; 36 \mathrm{~cm})$ para os anos de 2004; 2005 e 2006, respectivamente. Esse resultado é decorrente das funções desempenhadas pelo nitrogênio, como componente estrutural de macromoléculas e enzimas, envolvidas no processo de desenvolvimento vegetativo das plantas (MALAVOLTA, 2006).

Além disso, no que se refere a animais em condições de pastejo, a altura de plantas é um indicativo do aumento de quantidade de biomassa disponível, ou seja, uma maior oportunidade de ingestão de forragem pelos animais, pois a altura do pasto, até certo ponto, potencializa a profundidade do bocado que também é determinante da massa do bocado (CARVALHO et al., 2001).

O maior valor de altura de plantas em todos os anos estudados ocorreu em 2005, provavelmente, devido à melhor distribuição das chuvas naquele período (Figura 1). A maior altura de planta $(89 \mathrm{~cm})$ foi obtida em 2005 na dose de $300 \mathrm{~kg} \mathrm{ha}^{-1} \mathrm{ano}^{-1}$ e a menor $(30 \mathrm{~cm})$ no ano de 2004, sem aplicação de nitrogênio.

Avaliando a altura de plantas em relação às doses e fontes de nitrogênio, observa-se, que em ambas as fontes houve aumento da altura com as doses de nitrogênio aplicadas, com ajuste linear para o sulfato de amônio e para a uréia (Figura 2b). Na dose máxima, a altura das plantas mostrou aumento de $129 \%$ para o sulfato de

Figura 2 - Altura de plantas do capim-marandu em função das doses de nitrogênio para cada ano de recuperação (a) e fonte de nitrogênio (b). *Significativo a $5 \%$
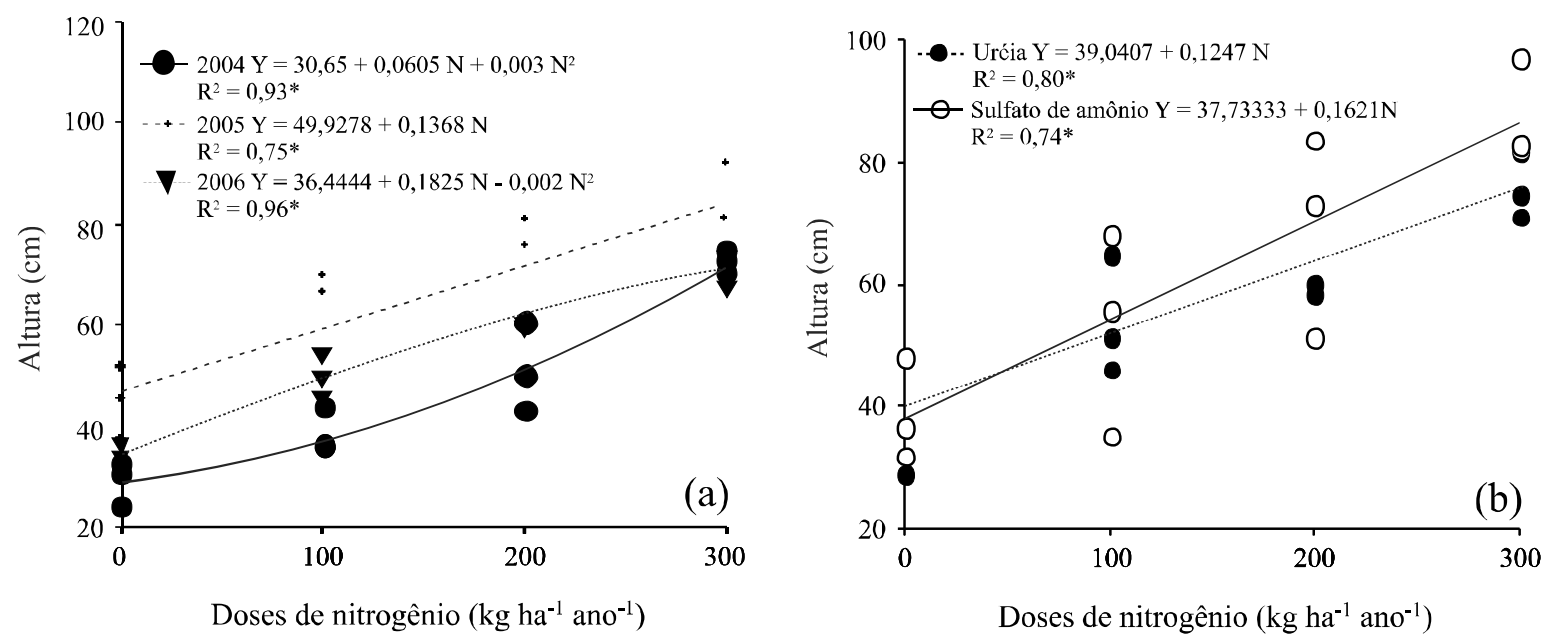
amônio e $96 \%$ para a uréia. A diferença entre as fontes de nitrogênio pode ter ocorrido devido às transformações da uréia na superfície do solo, resultando em grandes perdas de $\mathrm{N}$ para a atmosfera na forma de $\mathrm{NH}_{3}$ e $\mathrm{N}_{2} \mathrm{O}$ (MARTHA JÚNIOR et al., 2004).

Para a densidade de perfilhos houve interação $(\mathrm{P}<0,05)$ entre doses e anos de recuperação e doses e fontes de nitrogênio. Observa-se que houve aumento linear em relação às doses de nitrogênio para todos os anos de recuperação da pastagem (Figura 3a).

Os valores mais elevados para densidade de perfilhos ocorreram na dose de $300 \mathrm{~kg} \mathrm{ha}^{-1} \mathrm{ano}^{-1}$, mostrando aumento em relação a não aplicação de nitrogênio de 109; 122 e 114\% para os anos de 2004; 2005 e 2006, respectivamente. Esses resultados mostram que o capim-marandu apresenta alta capacidade responsiva à adubação nitrogenada e a ausência desse nutriente impede o aparecimento de novos perfilhos (PEREIRA et al., 2010), resultando na redução da produção de massa seca e no potencial de recuperação da pastagem degradada.

O nitrogênio exerce papel importante no desenvolvimento de perfilhos e, consequentemente, na produção de massa seca porque faz parte das proteínas e ácidos nucléicos, os quais participam ativamente da

Figura 3 - Densidade de perfilhos (número/m²) do capim-marandu em função das doses de nitrogênio para cada ano de recuperação (a) e fonte de nitrogênio (b). *Significativo a $5 \%$

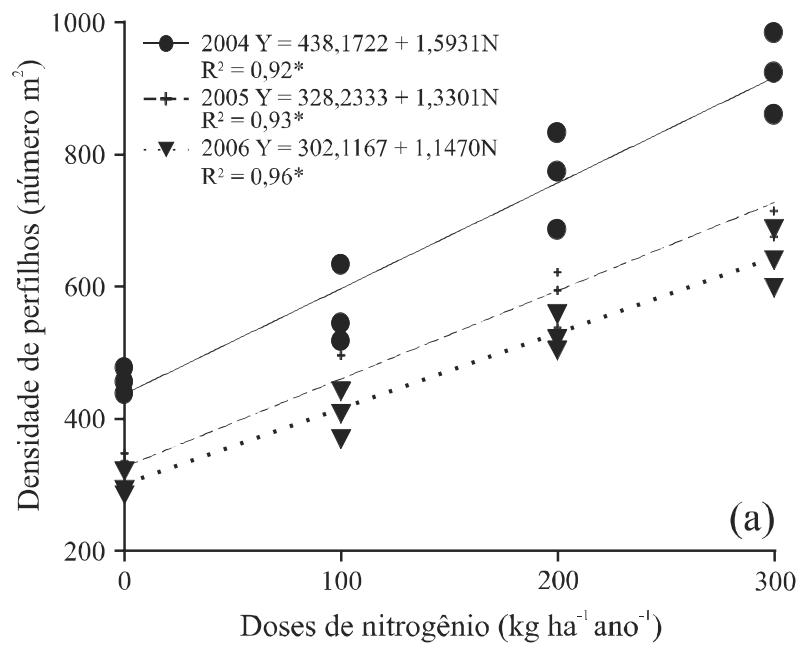

síntese de compostos orgânicos, que formam a estrutura do vegetal (MALAVOLTA, 2006).

Bonfim-da-Silva e Monteiro (2006), trabalhando com recuperação de pastagens degradadas do capimbraquiaria, sob doses de nitrogênio e enxofre, verificaram que o nitrogênio é o nutriente mais importante no número de perfilhos em forrageiras e que o aumento das doses de nitrogênio contribuiu efetivamente para o aumento da produção de massa seca das lâminas foliares e na recuperação da forrageira.

O nitrogênio provoca mudanças nas características estruturais da pastagem degradadae, dentre estas, mudanças na densidade populacional de perfilhos. A densidade de perfilhos apresentou comportamento diferenciado para os três anos de recuperação da pastagem. A maior densidade de perfilhos, em todas as doses de nitrogênio estudadas, foi observada no ano de 2004 e a menor, no ano de 2006.

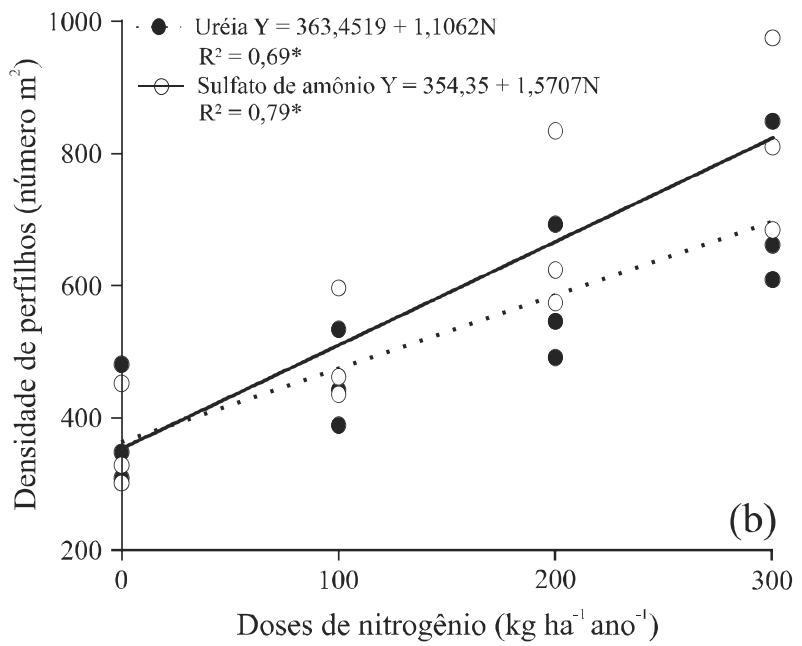

Provavelmente, essa queda na densidade de perfilhos, no último ano, foi ocasionada pela ocorrência de um veranico no mês de janeiro (Figura 1), que causou déficit hídrico de vinte dias, logo após a primeira aplicação da adubação nitrogenada, limitando com isso as respostas ao nitrogênio e prejudicando a produção de perfilhos. De fato, os processos de formação, desenvolvimento, crescimento e senescência de perfilhos são influenciados por condições climáticas, como temperatura e disponibilidade de água (CARVALHO et al., 2000).

Em relação às fontes estudadas, o sulfato de amônio promoveu maiores valores de densidade de perfilhos em relação à uréia, em todas as doses aplicadas. O sulfato de amônio proporcionou aumento de 8; 14 e 19\% nas doses de $100 ; 200$ e $300 \mathrm{~kg} \mathrm{ha}^{-1}$ ano $^{-1}$, quando comparado com a uréia (Figura 3b). Essa menor densidade de perfilhos nas áreas que tiveram a uréia como fonte de nitrogênio pode ser explicada em função das transformações desse 
fertilizante no solo, visto que a aplicação do nitrogênio foi realizada a lanço em cobertura, resultando, em maiores perdas de nitrogênio na forma de gases para a atmosfera (OLIVEIRA; TRIVELIN; OLIVEIRA, 2007), limitando, com isso, as respostas ao nitrogênio e prejudicando o desenvolvimento dos perfilhos. Outro fator que pode ter contribuído com a maior densidade de perfilhos com a utilização do sulfato de amônio, seria a presença de enxofre. Bonfim-da-Silva e Monteiro (2006) relatam que em áreas que recebem grandes quantidades de adubo nitrogenado, faz-se necessário o suprimento de enxofre

Figura 4 - Índice de área foliar (IAF) do capim-marandu em função das doses de nitrogênio. *Significativo a $5 \%$.

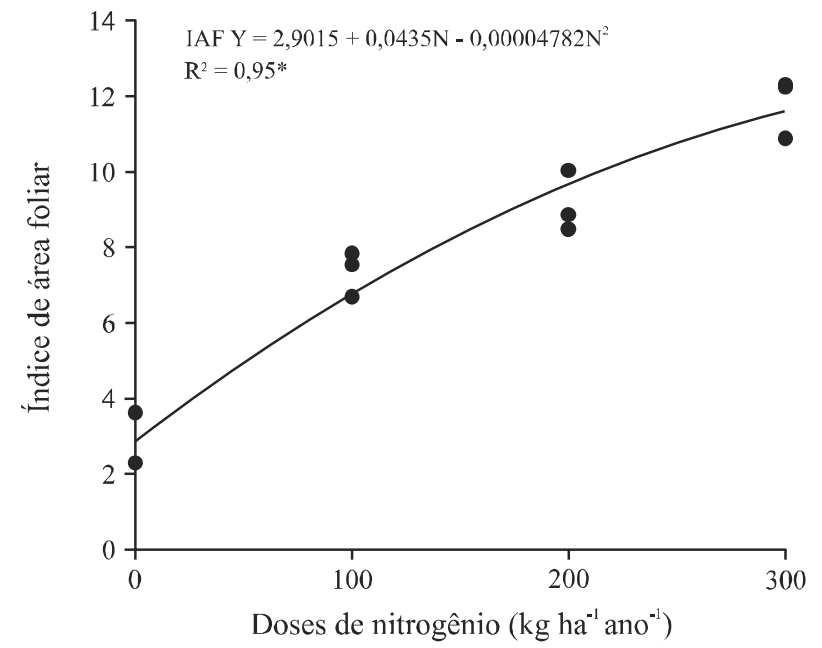

para maximizar a resposta da forrageira, principalmente em áreas degradadas com baixos teores de matéria orgânica onde, normalmente, os teores de enxofre-sulfato encontram-se pouco disponíveis no solo.

Não houve interação entre doses e anos de recuperação e doses e fontes de nitrogênio para o índice de área foliar (Figura 4), que apresentou aumento quadrático em função das doses de nitrogênio.

Como o índice de área foliar se refere à área de folhas por metro quadrado de terreno, esse efeito foi decorrente do aumento do tamanho das plantas (Figura 2a e 2b), ou seja, alongamento das folhas e do maior número de folhas devido à maior densidade de perfilhos (Figura 3a e 3b), obtidos com o aumento das doses de N.

As médias do índice de área foliar ficaram entre 2,90 e 11,65 para a testemunha e a dose máxima de nitrogênio, respectivamente, correspondendo ao aumento de $302 \%$, considerado relevante para o aumento da produção de forragem da pastagem e, consequentemente, para a recuperação da forrageira, devido à área foliar ser importante parâmetro utilizado para a análise do crescimento e desenvolvimento das plantas. Até certo ponto, quanto maior for a área foliar, maior será a superfície de exposição das folhas e, portanto, maior a capacidade fotossintética da planta o que, provavelmente, refletirá em uma maior capacidade produtiva da pastagem.

Em estudo conduzido para analisar a dinâmica de crescimento e nutrição do capim-marandu, submetido a diferentes doses de nitrogênio, Santos Jùnior e Monteiro (2003) verificaram que a área foliar do capim-marandu foi alterada positivamente pela aplicação de nitrogênio. Os resultados desse trabalho foram semelhantes aos obtidos por Rodrigues et al. (2006) com capim-xaraés.

As doses, fontes e anos derecuperaçãoinfluenciaram significativamente a produção de massa seca das lâminas foliares do capim-marandu. No desdobramento da interação doses e anos, o ajuste foi linear para os anos de 2004 e 2005 e quadrática para 2006, aumentando com as doses de nitrogênio aplicadas (Figura 5a).

A produção de massa seca das lâminas foliares apresentou comportamento diferenciado para os três anos de recuperação da pastagem estudados, onde a maior produção foi observada no ano de 2005, o que pode ser explicada devido à melhor distribuição das chuvas ocorridas neste ano (Figura 1), fato já discutido. Nos anos de 2004 e 2005, os maiores valores de produção de massa seca de lâminas foliares ocorreram na dose de $300 \mathrm{~kg}$ ha ${ }^{1} \mathrm{ano}^{-1}$. Já no ano de 2006, devido ao ajuste quadrático, ocorreu na dose de $255 \mathrm{~kg} \mathrm{ha}^{-1} \mathrm{ano}^{-1}$.

No ano de 2006, a menor resposta ao nitrogênio também pode ter sido influenciada pelos menores valores de $\mathrm{pH}$ do solo, associada a uma baixa disponibilidade de fósforo e potássio (Tabela 1).

A massa seca das lâminas foliares do ano de 2005, na dose de $300 \mathrm{~kg} \mathrm{ha}^{-1} \mathrm{ano}^{-1}$, foi superior em 49 e $73 \%$ à dos anos de 2004 e 2006, quando comparadas na mesma dose $(300 \mathrm{~kg} / \mathrm{ha} / \mathrm{ano})$, respectivamente. Com a aplicação de $300 \mathrm{~kg} \mathrm{ha}^{-1} \mathrm{ano}^{-1}$, os valores de massa seca das lâminas foliares foram $4.872 ; 7.273$ e $4.204 \mathrm{~kg} \mathrm{ha}^{-1}$, mostrando aumentos de $284 ; 122$ e $249 \%$ em relação à testemunha para os anos de 2004, 2005 e 2006, respectivamente.

No desdobramento de doses e fontes, a produção de massa seca das lâminas foliares apresentou aumento linear na fonte de sulfato de amônio e quadrático para a uréia. $\mathrm{O}$ sulfato de amônio proporcionou aumento na massa seca das lâminas foliares de 0,$9 ; 10 ; 25 \%$ nas doses de 100, 200, $300 \mathrm{~kg} \mathrm{ha}^{-1} \mathrm{ano}^{-1}$, quando comparado à uréia (Figura 5b).

A massa seca das lâminas foliares mostrou aumento de 212 e $151 \%$, na dose de $300 \mathrm{~kg} \mathrm{ha}^{-1} \mathrm{ano}^{-1}$, em relação a não aplicação de nitrogênio, respectivamente, para as fontes sulfato de amônio e uréia. De acordo com Silva et al. (2011), a maior produção de massa seca de folhas com a utilização do sulfato 
Figura 5 - Massa seca das lâminas foliares (MSLF) do capim-marandu em função das doses de nitrogênio para cada ano de recuperação (a) e fonte de nitrogênio (b). *Significativo a $5 \%$

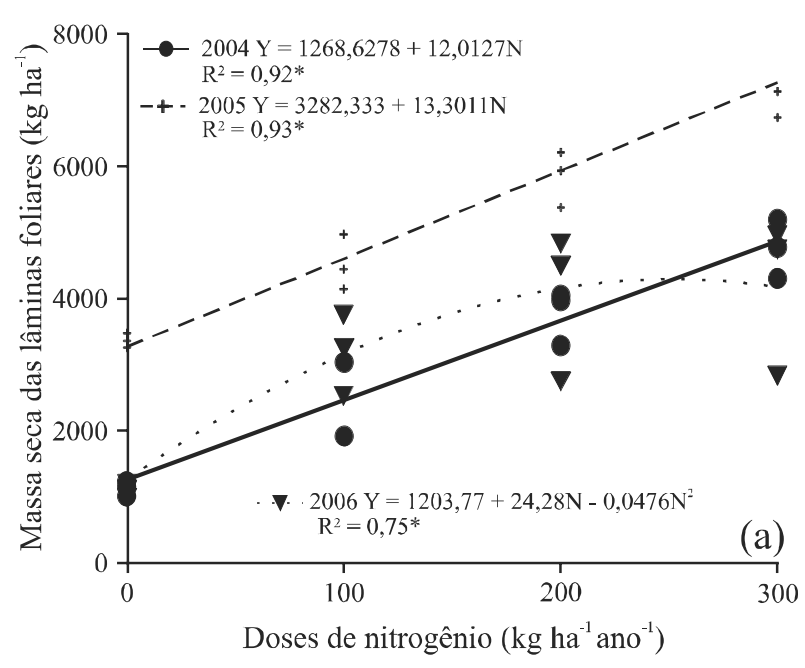

de amônio acima da dose de $111 \mathrm{~kg} \mathrm{ha}^{-1} \mathrm{ano}^{-1}$ ocorre devido às menores perdas de $\mathrm{N}$, enquanto que, com a utilização da uréia essas perdas de amônia para a atmosfera são mais acentuadas, promovendo menor eficiência da adubação nitrogenada e diminuindo a resposta da planta em produção por unidade de $\mathrm{N}$ aplicado.

A produção de massa seca de colmos e bainhas não foi influenciada $(\mathrm{P}>0,05)$ pela interação de doses e anos de recuperação e doses e fontes de nitrogênio. Entretanto, houve efeito $(\mathrm{P}<0,05)$ isolado das doses de nitrogênio, com ajuste linear crescente (Figura 6).

Na dose máxima aplicada, observou-se aumento da massa seca, de colmo mais bainha, de $239 \%$ em relação a não aplicação de nitrogênio. Em estudos com doses de nitrogênio e enxofre em pastagem degradada de capim-braquiária, Bonfim-da-Silva e Monteiro (2006), verificaram que as doses de nitrogênio foram determinantes para a produção de massa seca das lâminas foliares e dos colmos mais bainhas. Aumentos na produção de lâminas foliares e colmos relacionados à adubação nitrogenada no capim-marandu também foram obtidos por Santos Júnior e Monteiro (2003).

De acordo com Alexandrino et al. (2005) a baixa acumulação de massa seca de colmos mais bainhas das plantas forrageiras, na ausência de adubação nitrogenada, deve-se ao menor alongamento do colmo e ao baixo perfilhamento. A produção de massa seca de colmos e bainhas é componente relevante para a produção de forragem, pois os colmos e bainhas são órgãos armazenadores de substâncias orgânicas nas gramíneas, o que pode interferir na capacidade de rebrota dos capins.

A relação folha:colmo mais bainhas é variável de grande importância para a avaliação das plantas forrageiras.

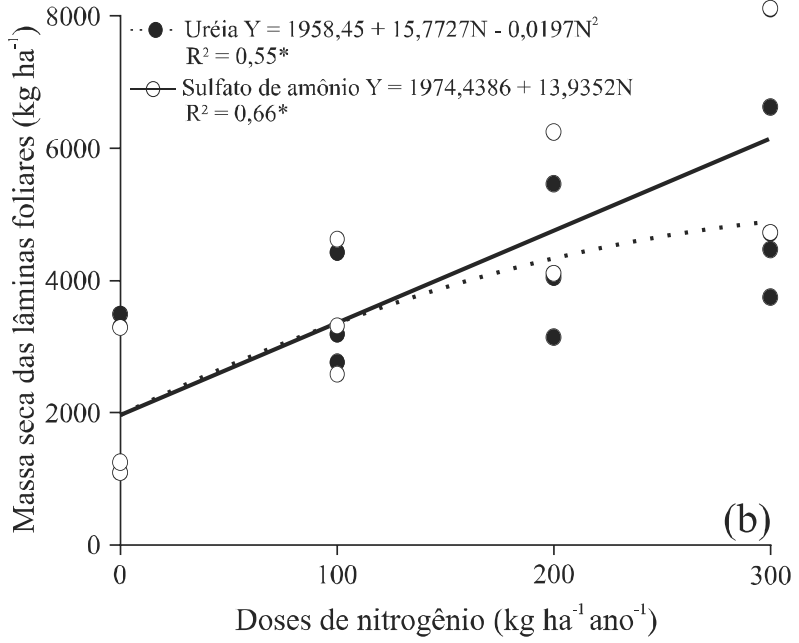

Figura 6 - Massa seca dos colmos mais bainhas (MSCB) do capimmarandu em função de doses de nitrogênio. *Significativo a 5\%

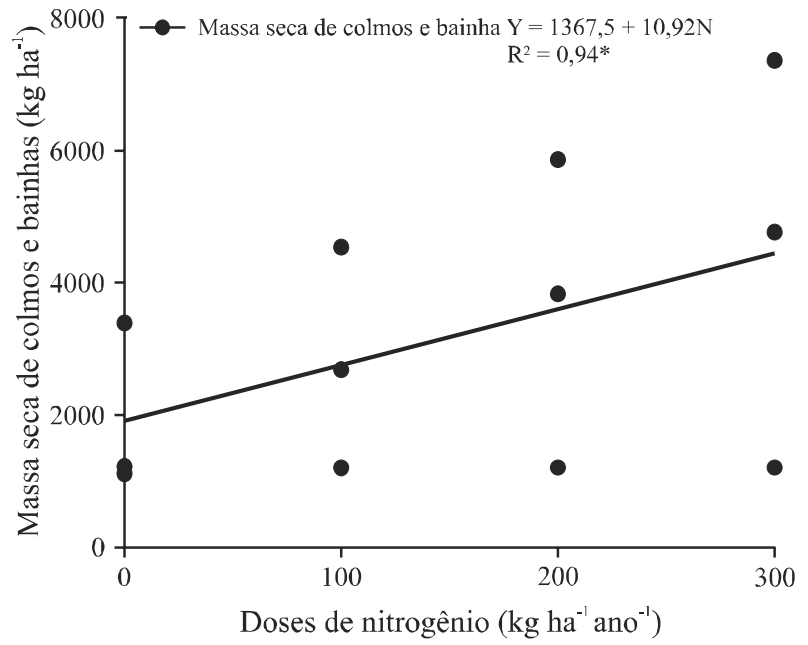

Alta relação representa forragem com elevada concentração de proteína e digestibilidade, com possibilidade de alto consumo por animais, capaz de atender às exigências nutricionais dos ruminantes, garantindo maior ganho de peso ou produção de leite dos animais. Do mesmo modo, a alta relação folha:colmo mais bainhas confere à gramínea melhor adaptação ao pastejo ou tolerância ao corte, por apresentar momento fenológico em que os meristemas apicais se apresentam mais próximos ao solo e, portanto, menos vulneráveis à destruição no pastejo.

No presente trabalho a relação folha:colmo mais bainhas não foi influenciada $(\mathrm{P}>0,05)$ pelas doses, fontes e anos de recuperação e pelas interações desses fatores. 
O capim-marandu em recuperação tem dependência das doses e fontes de nitrogênio para a altura das plantas, densidade de perfilhos e para a massa seca das lâminas foliares, em todos os anos avaliados. Doses de até $300 \mathrm{~kg} \mathrm{ha}^{-1} \mathrm{ano}^{-1}$ de nitrogênio tiveram efeito positivo sobre as características estruturais e produtivas e, consequentemente, sobre a recuperação do pasto degradado. O sulfato de amônio foi superior a uréia para: altura de plantas e massa seca de lâminas foliares, e para densidade de perfilhos ocorreu o inverso. A altura de plantas e a densidade de perfilhos foram mais elevadas no segundo ano de recuperação do pasto, devido aos fatores relatados anteriormente, para a altura de plantas e densidade de perfilhos, como volatilização, desnitrificação e lixiviação.

\section{CONCLUSÕES}

A adubação nitrogenada teve efeito positivo sobre as características estruturais e produtivas e, consequentemente, sobre a recuperação da pastagem de capim-marandu. Os maiores valores de altura de plantas, densidade de perfilhos e massa seca das lâminas foliares ocorreram na dose de $300 \mathrm{~kg} \mathrm{ha}^{-1} \mathrm{ano}^{-1}$ de $\mathrm{N}$ aplicada na forma de sulfato de amônio.

\section{REFERÊNCIAS}

ALEXANDRINO, E. et al. Características morfogênicas e estruturais da Brachiaria brizantha cv. Marandu submetida a diferentes doses de nitrogênio e frequências de cortes. Acta Scientiarum Agronomy, v. 27, n. 01, p. 17-24, 2005.

BONFIM-DA-SILVA, E. M.; MONTEIRO, F. A. Nitrogênio e enxofre em características produtivas do capim-braquiária proveniente de área de pastagem em degradação. Revista Brasileira de Zootecnia, v. 35, n. 04, p. 1289-1297, 2006.

BRAGA, G. J. et al. Fotossíntese e taxa diária de produção de forragem em pastagens de capim-tanzânia sob lotação intermitente. Pesquisa Agropecuária Brasileira, v. 44, n. 01, p. 84-91, 2009.

CARVAlHO, P. C. F. et al. Importância da estrutura da pastagem na ingestão e seleção de dietas pelo animal em pastejo. In: REUNIÃO ANUAL DA SOCIEDADE BRASILEIRA DE ZOOTECNIA, 20,, 2001, Piracicaba. Anais... Piracicaba: FEALQ/SBZ, 2001. p. 853-871.

CARVALHO, C. A. B.; SILVA, S. C.; CARNEVALLI, R.A. et al. Perfilhamento e acúmulo de forragem em pastagens de Florakirk (Cynodon spp.) sob pastejo. Boletim da Indústria Animal, v. 57, n. 01, p. 39-51, 2000.

COSTA, K. A. P et al. Produção de massa seca e nutrição nitrogenada de cultivares de Brachiaria brizantha (A. Rich) Stapf sob doses de nitrogênio. Ciência e Agrotecnologia, v. 33, n. 06, p. 1578-1585, 2009.
EMPRESA BRASILEIRA DE PESQUISA AGROPECUÁRIA. Sistema brasileiro de classificação de solos. 2. ed. Rio de Janeiro: Embrapa CNPS, 2006. 306 p.

EUCLIDES, V.P.B. etal.Eficiência biológica e econômica de pasto de capim- tanzânia adubado com nitrogênio no final do verão. Pesquisa Agropecuária Brasileira, v. 42, n. 09, p. 1345- 1355, 2007.

FERREIRA, D. F. Programa de análises estatísticas (Statistical Analysis Software) e planejamento de experimentos. Lavras: Universidade Estadual de Lavras, 2003.

FLORES, R. S. et al. Desempenho animal, produção de forragem e características estruturais dos capins marandu e xaraés submetidos a intensidades de pastejo. Revista Brasileira de Zootecnia, v. 37, n. 08, p. 1355-1365, 2008.

MALAVOLTA, E. Manual de nutrição mineral de plantas. São Paulo: Ceres, 2006. 638 p.

MARTHA JÚNIOR, G. B. et al. Perdas de amônia por volatilização em pastagem de capim-tanzânia adubada com uréia no verão. Revista Brasileira de Zootecnia, v. 33, n. 06, p. 2240-2247, 2004.

MESQUITA, P. et al. Structural characteristics of marandu palisadegrass swards subjected to continuous stocking and contrasting rhythms of growth. Scientia Agricola, v. 67, n. 01, p. 23-30, 2010.

OLIVEIRA,P.P.A.; TRIVELIN, P.C. O.; OLIVEIRA, W. S. Balanço do nitrogênio $\left({ }^{15} \mathrm{~N}\right)$ da uréia nos componentes de uma pastagem de capim-marandu sob recuperação em diferentes épocas de calagem. Revista Brasileira de Zootecnia, v. 36, n. 06, p. 1982-1989, 2007.

PEREIRA, L. E. T. et al. Sward structure of marandu palisadegrass subjected to continuous stocking and nitrogen-induced rhythms of growth. Scientia Agricola, v. 67, n. 05, p. 531-539, 2010.

RODRIGUES, R. C. et al. Densidade populacional de perfilhos, produção de massa seca e área foliar do capim-xaraés cultivado sob doses de nitrogênio e potássio. Boletim de Indústria Animal, v. 63, n. 01, p. 27-33, 2006.

SANTOS JÚNIOR, J. D. G.; MONTEIRO, F. A. Nutrição de capimmarandu submetido a doses de nitrogênio e idades de crescimento. Boletim da Indúsria Animal, v. 60, p. 139-146, 2003.

SANTOS, I. P. A. et al. Frações de fósforo em gramíneas forrageiras tropicais sob fontes e doses de fósforo. Ciência e Agrotecnologia, v. 30, n. 05, p. 961-970, 2006.

SANTOS, M. E. R. et al. Estrutura do pasto de capimbraquiária com variação de alturas. Revista Brasileira de Zootecnia, v. 39, n. 04, p. 2125-2131, 2010.

SILVA, D. R. G. et al. Eficiência nutricional e aproveitamento do nitrogênio pelo capim-marandu de pastagem em estágio moderado de degradação sob doses e fontes de nitrogênio. Ciência e Agrotecnologia, v. 35, n. 02, p. 242-249, 2011.

SOUSA, D. M. G.; LOBATO, E. Cerrado: correção do solo e adubação. 2. ed. Brasília, Embrapa Informação Tecnológica, 2004. 416 p.

WERNER, J. C.; COLOZZA, M. T.; MONTEIRO, F. A. Adubação de pastagens. In: PEIXOTO, A. M.; MOURA, SILVA, S. C. da; J. C. de; FARIA V. P. de (Ed.). SIMPÓSIO SOBRE MANEJO DE PASTAGENS, 18, 2001, Anais... Piracicaba: FEALQ, 2001., p. 129-156. 